\title{
THE CLEMENTINE NICKEL HYDROGEN COMMON PRESSURE VESSEL BATTERY
}

\author{
J. Christopher Garner \\ U.S. Naval Research Laboratory, Washington, D.C.
}

\section{Abstract}

The Clementine spacecraft was launched in January 1994 to demonstrate advanced lightweight technologies for the Ballistic Missile Defense Organization (BMDO). One of the key technologies was the first use of a multi-cell nickel hydrogen $\left(\mathrm{NiH}_{2}\right)$ common pressure vessel (CPV) battery. The 5.0 inch diameter, 22 cell, 15.0 ampere-hour $\mathrm{NiH}_{2} \mathrm{CPV}$ battery was manufactured by Johnson Controls Battery Group Inc., (JCBGI). Battery test and integration was performed by the Naval Research Laboratory (NRI). The battery was mounted to the spacecraft using a unique, lightweight graphite epoxy structure. An integral mounted pressure transducer provided battery pressure data for a pressure based charge control method. Along with the structure and the charge control method, this paper will discuss the battery design trade study, pre-launch battery data and on-orbit performance data.

\section{Introduction}

In 1992, NRL reported on a joint NRL-JCI cooperative research and development agreement to fly a JCI NiH2 CPV battery experiment ${ }^{1}$. In the agreement, JCI delivered two batteries to NRL who provided battery testing and integration with a host spacecraft. That year, the experiment was released to the Air Force for assignment on a ride of opportunity in 1993. Later that year, NRL was informed that the assigned payload did not achieve orbit and the $\mathrm{NiH}_{2} \mathrm{CPV}$ experiment was lost. Despite the loss, NRL was anxious for another flight opportunity. Data from the two batteries was excellent and NRL continued to life cycle the qualification battery at $400^{\circ} \mathrm{DOD}, 15^{\circ} \mathrm{C}$. Later that year, the clementine mission provided the opportunity demonstrate the capabilities of the NiH2 CPV. Clementine's mission required an energy storage system to support spacecraft eclipses in low earth, lunar and transfer orbits. Eclipse periods ranged from 35 minutes in LEO to 120 minutes during the transfer orbits. In a design trade study, the multi-cell $\mathrm{NiH}_{2}$ CPV was compared to nickel cadmium, IPV $\mathrm{NiH}_{2}$, and 2-cell $\mathrm{NiH}_{2} \mathrm{CPV}$ batteries. With a specific energy of $47 \mathrm{Wh} / \mathrm{kg}$ the multicell $\mathrm{NiH}_{2} \mathrm{CPV}$ was the best choice for the weight critical mission. The clementine spacecraft was launched in January 1994 and the multi-cell $\mathrm{NiH}_{2} \mathrm{CPV}$ battery has supported both low earth orbit and over 300 lunar eclipses.

This paper describes the multi-cell $\mathrm{NiH}_{2}$ CPV battery and its impact on the Clementine battery design, electrical power system concept, and general mechanical and thermal spacecraft interfaces. Battery performance data from launch through the lunar mapping phase is also described.

\section{Spacecraft Descriotion}

The overall configuration of the spacecraft is shown in Figure 1.

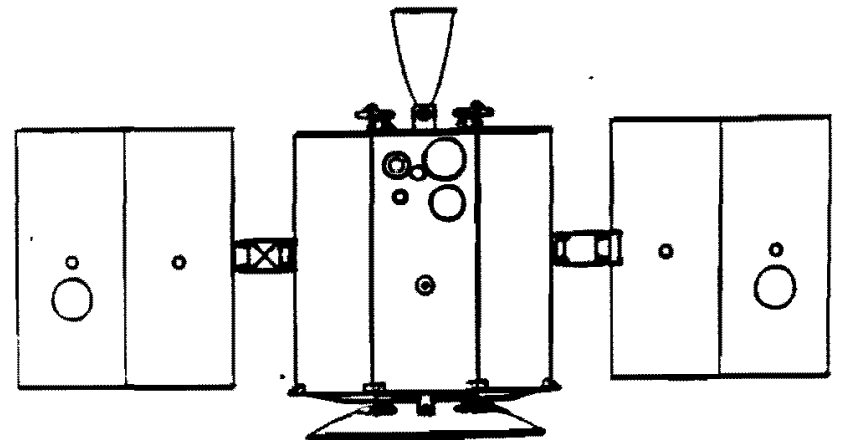

Figure 1, Clementine Spacecraft

The spacecraft body has the shape of a right octagonal prism, approximately 1.11 $\mathrm{m}(43.45 \mathrm{in})$ wide and $1.07 \mathrm{~m}(41.73 \mathrm{in})$ thick.The spacecraft is 3-axis stabilized with reaction wheels and attitude control thrust jets. A $110 \mathrm{lb}$ thruster is used for $\Delta \mathrm{V}$ maneuvers. A deployed GaAs/Ge solar array generates $380 \mathrm{~W}$ a $30 \mathrm{VDC}$. The solar array can be rotated autonomously through the spacecraft y-axis.

The spacecraft was shipped from NRI to Vandenberg Air Force Base on January 6, 1994 and launched 19 days later onboard a Titan II launch vehicle. After one week in 
a low earth orbit the auxillary solid rocket motor was fired and clementine was on the way to the Moon. Insertion into a lunar polar orbit with an 5 hour period occurred on Eebruary 19. No eclipse periods were encountered at the start of the lunar mapping, but several days later, the eclipses started, and by the middle of the mapping mission the maximum eclipse period was 75 minutes. On May 2, 1994 the spacecraft burned the $110 \mathrm{lb}$ thruster and departed the lunar orbit for a rendezvous with the Asteroid Geographos.

\section{Electrical Power Subsystem Design}

The Clementine electrical power subsystem is a simple, lightweight, direct energy transfer design. 2 The $\mathrm{NiH}_{2} \mathrm{CPV}$ battery is directly connected to the bus to regulate the bus voltage to $30 \pm 6$ vdc. Electrical power from the GaAs/Ge solar arrays is distributed to the mission loads and to charge the $\mathrm{NiH}_{2}$ CPV battery. The battery charge control method used is based on the linear increase of battery pressure with state of charge. A pressure transducer mounted on the battery provides a 0 to 10 volt output which corresponds to a battery pressure of 0 to 1000 psi. Charge current regulation is achieved by pulse width modulating a series of FET switches. The switches disconnect/connect solar array strings to maintain a high rate charge current of 3.0 amperes. When the battery pressure equals $600 \mathrm{psi}$, the charge control circuitry reduces the charge rate to 0.150 amperes.

\section{Energy storage Requirements}

The Clementine energy storage system is required to support orbit eclipses in low earth, lunar, and transfer orbits. The duration and power required for each type of eclipse is shown below in Table 1 .

$\begin{array}{lcccc}\text { Phase } & \text { Dur (minl } & \text { Ioad (W) } & \text { Cycles } \\ \text { LEO } & 36 & 146 & 144 \\ \text { Lunar } & 75 & 226 & 370 \\ \text { Transfer } & 123 & 121 & 3\end{array}$

Table 1, Energy Storage Requirements

$$
\text { Selection of } \mathrm{NiH}_{2} \mathrm{CPV} \text { Battery }
$$

Based on the requirements listed in Table 1 , a battery capacity of 15.0 ampere-hours (Ah) was selected to perform the mission. The maximum depth of discharge (DOD), defined as: DOD = Ahout/Ahcapacity, for the three phases is; LEO (21\%), Lunar (65\%) and Transfer (60\%). Life cycle test data indicates that most secondary, nickel positive plate battery technologies are capable of achieving thousands of cycles at $60 \%$ DOD.3 Three readily available technologies were investigated; Aerospace nickel-cadmium, (2) two-cell CPV nickel hydrogen, and (3) multi-cell CPV nickel hydrogen. A $15.0 \mathrm{Ah}$, twenty-two cell battery of each design technology was compared in a trade study. Table 2 shows the results of the trade study.

$\begin{array}{lccc}\text { Parameter } & \text { NiCd } & \text { NiH2 } & \text { NiH2 } \\ \text { Config } & 22 \text { cel1s } & 11-2 \mathrm{Ce} 11 & 22 \text { cel1 CPV } \\ \text { Length } & 0.2489 & 0.3850 & 0.5080 \\ \text { Width } & 0.1613 & 0.2540 & 0.1334 \\ \text { Height } & 0.1636 & 0.2540 & 0.1334 \\ \text { Mass (kg) } & 16.95 & 12.71 & 9.53 \\ \text { Vol (1) } & 6.57 & 50.00 & 8.61 \\ \text { Wh/kg } & 26.53 & 27.37 & 47.13 \\ \text { Wh/1 } & 50.23 & 6.60 & 38.33\end{array}$

Table 2, Battery Technology Comparison

Clearly, at 15.0 Ah the multi-cell NiH2 CPV battery was the best choice for specific energy (Wh/ $\mathrm{kg})$. Energy density of the multi-cell cpv is much better than the 2-cell cpv but not as good as the easily packaged prismatic Nicd battery cells.

\section{The JCBGI 15,0 Ah NiH2 CPV Battery}

The 15 Ah CPV NiHz battery consists of 22 series connected cells. The $12.7 \mathrm{~cm}\left(5^{\prime \prime}\right)$ diameter circular cells employ a back-toback nickel electrode configuration with three modules per cell. Nickel electrodes are $0.081 \mathrm{~cm}\left(0.032^{\prime \prime}\right)$ thick and utilize wet slurry plaque which were impregnated via an aqueous electrochemical process. Theoretical capacity based on total active material is $15.75 \mathrm{Ah}$, derated to a nominal capacity of $15.0 \mathrm{Ah}$. The battery vessel is composed of $0.0762 \mathrm{~cm}\left(0.030^{\prime \prime}\right)$ thick Inconel 718 that has been qualified for operation at 725 psig per MII-STD-1522A. pressure is monitored via a single pressure transducer. General aspects of the CPV design have been presented previously.4,5 clementine acceptance test data is sumnarized below in Table 3 . 
Temperature

$0^{\circ} \mathrm{C} \quad 10^{\circ} \mathrm{C} \quad 20^{\circ} \mathrm{C}$

$\begin{array}{lllll}\text { Capacity to } 22 \mathrm{~V} & \text { (Ah) } & 14.5 & 14.7 & 12.8\end{array}$

$\begin{array}{llll}\text { Mid-Discharge Volt/Cell } & 1.24 & 1.25 & 1.25\end{array}$

Impedance $(\mathrm{m} \Omega, 1008$ SOC 71

$1 \mathrm{kHz}$

Charge Retention (Ah, $72 \mathrm{~h}$ stand)

8.9

Table 3, Clementine Battery Acceptance Test Data

\section{Battery Mechanical/Thermal Desion}

The NRI packaging designers were given a design goal of $15 \%$ for the mounting structure to battery mass ratio. $\mathrm{NiH}_{2}$ battery operating characteristics dictated that the thermal control design maintain the battery temperature between 0 to 15 deg $C$. The battery/structure had to withstand launch loads of 19.8 GRMS over 20 to $2000 \mathrm{~Hz}$ in all three axis. Current work by engineers at NRI suggested that a graphite composite structure could meet the requirements. By using a combination of Amaco P120 and T300 graphite fibers, the final design resulted in a lightweight 2.63 lb structure with a structure to battery mass ratio of $14 \%$. The structure, shown in Figure 2, provides a lightweight method of attaching the cylindrical battery to a flat surface and provides semi-passive thermal control. The highly thermal conductive $P 120$ fibers are wrapped around the pressure vessel circumference and formed into a mounting base. Heat transfer is by conduction along the length of the fiber. Thus heat generated by the battery is conducted from the pressure vessel along the fiber to the battery structure flange. T300 fibers are sandwiched between the P120 fibers to provide structural integrity.

$\mathrm{NiH}_{2} \mathrm{CPV}$ Battery

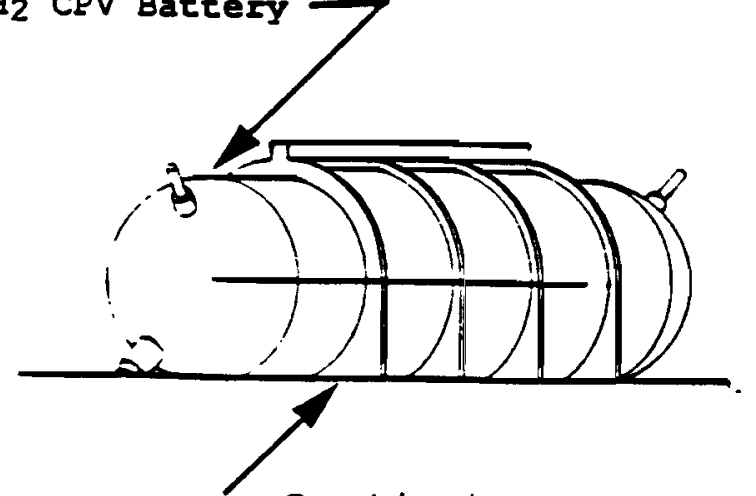

Graphite/Epoxy Structure Figure 2, Mechanical/Thermal structure
The battery structure flange is bolted to the interior side of a shear panel on the spacecraft $+Z,-Y$ side. The 0.375 inch thick shear panel is constructed of aluminum honeycomb with aluminum facesheets. The exterior side of the shear panel is covered with silver teflon tape to create a radiating surface with a high emissivity. To maintain the battery temperature above $0^{\circ} \mathrm{C}$, thin film resistive heaters were adhesively bonded to the graphite structure and covered with Aluminum tape. The heaters are thermostatically controlled to turn on at $6^{\circ} \mathrm{C}$ and turn off at $12^{\circ} \mathrm{C}$.

\section{Battery Charge Control Method}

Data from the NRL-JCI flight experiment batteries showed excellent correlation between battery state of charge and battery pressure. Battery hydrogen pressure increases linearly with the battery state of charge and at full charge, the slope of the pressure curve levels. This characteristic of the $\mathrm{NiH}_{2}$ battery was used to design the charge control system. To establish the slope and end of charge pressure curve, two batteries were characterized under the following test conditions: a 3.0 amp charge to voltage rollover, followed by a -7.5 amp discharge to 22.0 volts. Test temperatures were varied from $-5^{\circ} \mathrm{C}$ to $+20^{\circ} \mathrm{C}$ in $5^{\circ} \mathrm{C}$ increments. The results are plotted below in Fig. 3 .

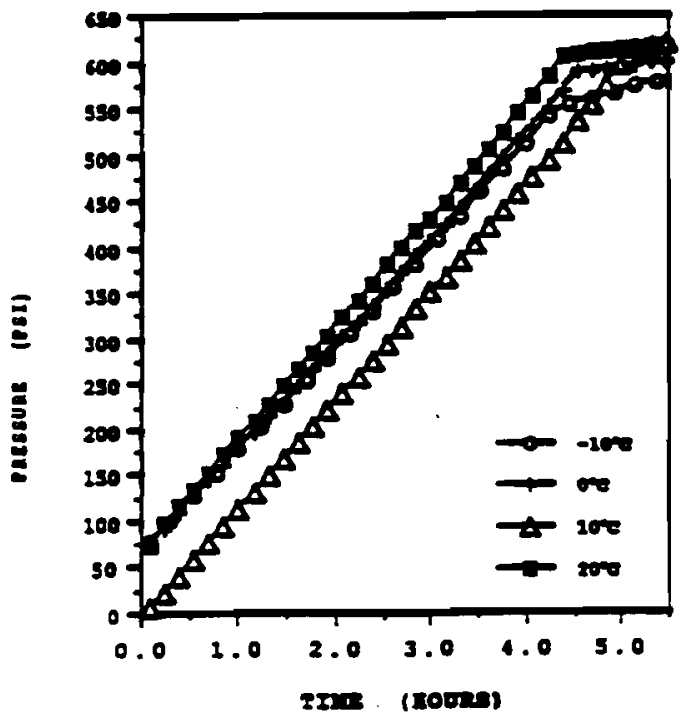

Figure 3, Battery Pressure Characterization Curve 
The tests indicated that independent of temperature, the battery was fully charged at a battery pressure of 600 psi. Further charging was inefficient and caused the battery temperature to rapidly increase. Based on this information a two-step charge method was designed. First, the battery would charge at 3.0 amperes until the battery pressure was equal to $600 \mathrm{psi}$. Then at 600 psi, the charge rate is reduced to a trickle of 0.150 amperes. To allow for the need of a higher recharge fraction on orbit, an alternate commandable trickle charge rate of 0.750 amperes was added. A circuit hysteresis of 20 psi was designed in so that the 3.0 amp charge would not initiate unless the battery pressure was below 580 psi. To allow for possible pressure growth on orbit, an additional pressure set point of 670 psi was added to the charge control electronics.

\section{Spacecraft Intecration}

The first battery shipped to NRI was designated as the qualification battery. The battery was serial number 119 from JCBGI. After completing the normal electrical characterization tests, the battery was subjected to a $3 \mathrm{C}$ peak load test, random vibration, thermal vacuum and shock tests. A rattling noise could be heard inside the battery after the first axis of the random vibration test,. The battery pressure transducer was removed and by tilting the battery on end, a nut could be seen loose inside the battery. The battery was returned to JCBGI for analysis. Analysis by JCBGI revealed that one of the tie rod nuts backed completely off. The remaining nuts were intact, but a torque measurement on each nut indicated some relaxation from the original torque value. The locking nuts used are the spiralock type. The thread of these nuts have a unique locking feature not a locking nylon insert. The locking feature can be disabled by removing the pre-load on the bolt. Thus it was theorized that the pre-load on the nut may have been relaxed due to movement of the battery cell stack during the vibration test. As a fix, belleville washers were added to the tie rods to maintain the proper pre-load during vibration. The battery was shipped back to NRI for re-test and completed all qualification tests.
The "Qual" battery was installed on the engineering model spacecraft for systems checkout. Systems checkout included verifying the charge control system, battery telemetry points, and fit checking the mechanical interface. Next, the battery supported the spacecraft EMI/EMC test. The EMI/EMC test was conducted in a non-temperature controlled anechoic chamber. The average temperature of the battery during the test was $28^{\circ} \mathrm{C}$. During non-test periods the average battery temperature was $25^{\circ} \mathrm{C}$. The

"warm" temperatures combined with long periods of open circuit stand lead to a capacity degradation. During the transition from engineering model spacecraft to flight spacecraft, $s / \mathrm{n}$ 119 was returned to the laboratory for post integration testing. Several standard capacity tests (defined as a 1.5 amp charge for 16 hours, followed by a -7.5 amp discharge to 22.0 volts) were conducted and the results indicated a capacity loss or fade of $33 \%$. Such a loss of capacity could not be tolerated on the flight battery. Thus, before integrating $\mathrm{s} / \mathrm{n} 120$ with the flight spacecraft, several procedural changes were made. The first change was to lower the ambient temperature of the test area so that internal spacecraft temperature were below $20^{\circ} \mathrm{C}$. After one week of working in a temperature environment of $15^{\circ} \mathrm{C}$, the spacecraft integrators revolted, and a small temperature chamber was installed near the flight spacecraft. The second change was to only install the battery in the spacecraft when absolutely required and to maintain a trickle charge on the battery at all times. The last change was to discharge the battery to 22.0 volts when battery was not in use and store it in the temperature chamber. Once the procedures and awareness were in place, integration of the battery went smoothly.

\section{On-orbit Performance}

The final battery charged was initiated on January 18, 1994. The battery was charged at a $C / 20=0.75$ amperes rate for a period of 25 hours. The charge rate was reduced to 0.150 amperes and remained at that rate up until launch. Launch was on January 25 , 1994 at 08:35. For the first day in orbit, the spacecraft was in a controlled tumble and maintaining a good power/thermal balance. By the second day, the reaction wheels were spun up and the spacecraft was oriented to maintain the sun normal to the 
stowed solar array panels. The battery was charging up to 600 psi and going into trickle charge. However, several orbits later, an error in the attitude control software, allowed the spacecraft attitude to drift until the sun was now parallel to the stowed solar panels. Subsequently, the battery was now supporting most of the spacecraft load. After several orbits, the battery pressure and voltage degraded rapidly to less than 22 volts and 90 psi. As the pressure decreased below 90 psi, the spacecraft controller performed a battery under-pressure command and switched off all non-critical spacecraft loads. In the scramble to determine what happened, contact with the spacecraft was lost for several orbits. Twenty hours later, contact was re-established with the spacecraft and the battery pressure was approximately 200 psi. A plot of battery pressure versus initial time on orbit is depicted in Fig.4. Ground station passes were occurring during eclipse such that the transmitter load was causing the battery to discharge. Thus the transmitter was activated only long enough to acquire spacecraft attitude and battery state of charge (pressure) data. Several orbits later when the battery pressure had increased to 300 psi or 508 state of charge, the ground station commanded the spacecraft to orient the solar panels normal to the sun. With the solar panels normal to the sun, high rate charging was possible and within several orbits the battery was fully charged.

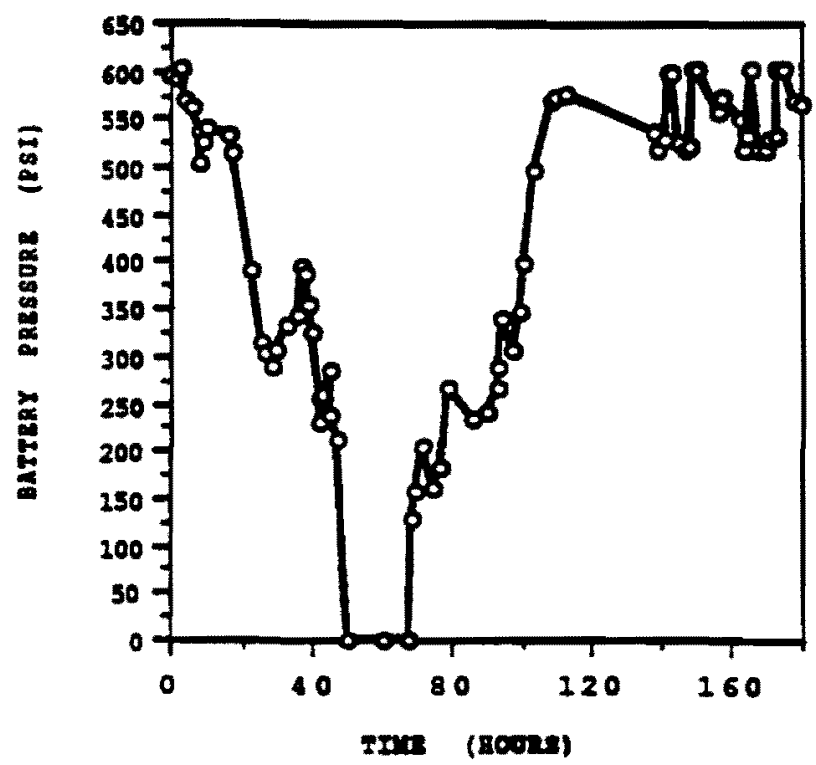

Eigure 4, NiH2 CPV Pressure vs Time After Launch
One day before the spacecraft lunar orbit insertion, the solar arrays were intentionally pointed away from the sun to allow the battery to discharge at a -7.0 ampere rate. The battery was discharged for 90 minutes. By extrapolating the pressure data, Fig. 5, out to 120 minutes, the capacity of the battery calculates to 14.1 ampere-hours, which is within. I ampere-hours of the pre-launch capacity.

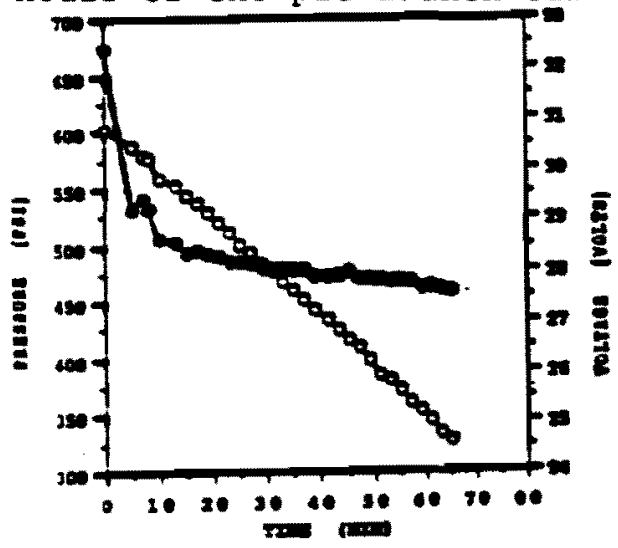

Figure 5, Pre-Lunar Discharge Test

The spacecraft was inserted into lunar orbit on the morning of February 19. The $\mathrm{NiH}_{2} \mathrm{CPV}$ battery performed flawlessly and supported over 350 lunar orbits. Battery pressure, current, and temperature during the Lunar mapping are shown in Figures 6 and 7 . During the maximum eclipse period of 75 minutes, the end of discharge pressure and voltage measured $320 \mathrm{psi}$ and 26.5 volts.

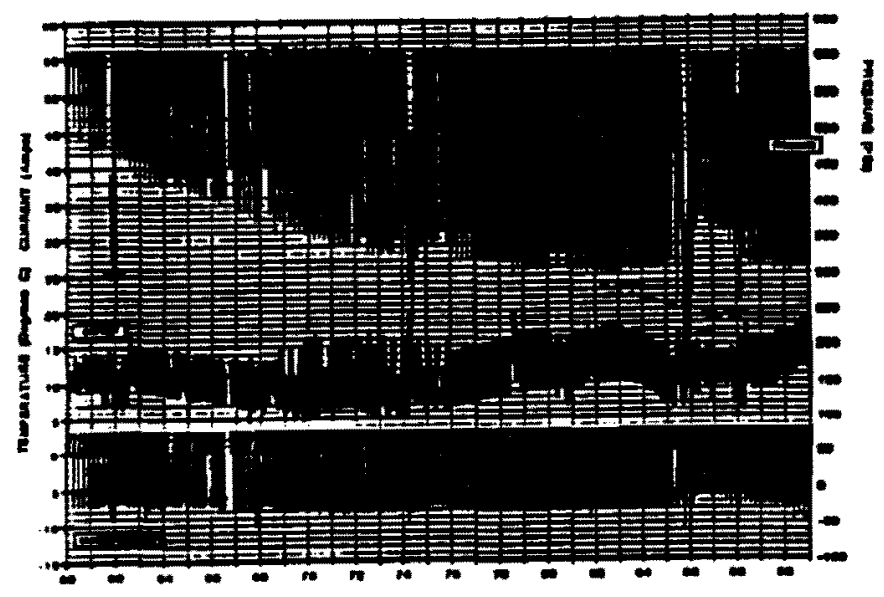

Figure 6, Lunar Mapping Data (March) 


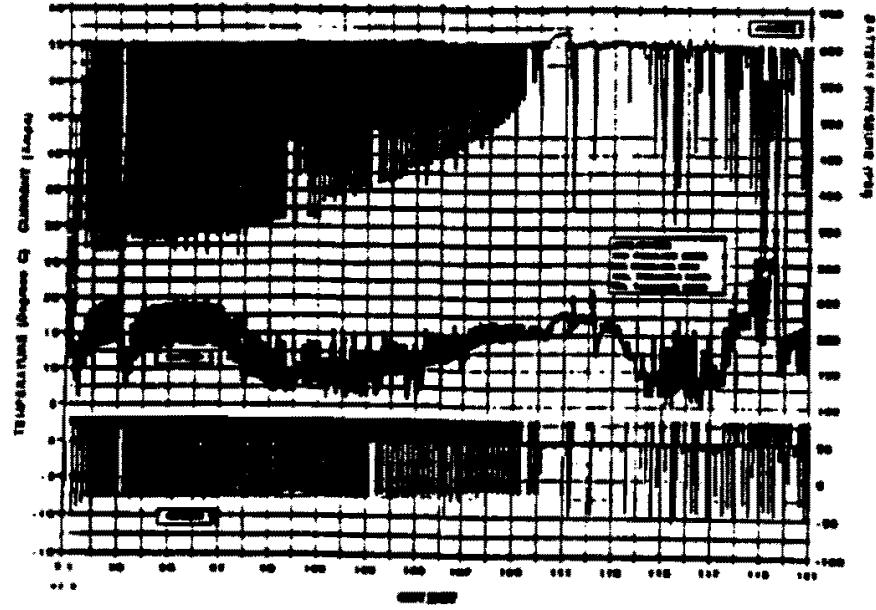

Figure 7, Lunar Mapping Data (April)
(4) J.Zagrodnik and K.Jones, "Advances In The Design of Common Pressure Vessel Nickel Hydrogen Batteries For Aerospace Applications, " Proceedings of The 26th Intersociety Energy Conversion Engineering Conference, August 1991

(5) J.Zagrodnik and K.Jones, "NickelHydrogen Multi-cell Common Pressure Vessel Battery Development Update," Proceedings of The $27 \mathrm{th}$ Intersociety Energy Conversion Engineering Conference, August 1992

\section{Conclusions}

A $\mathrm{NiH}_{2}$ CPV battery was designed and fabricated by NRI and JCBGI. The battery successfully met the test requirements established by NRL to qualify it for flight use. With the use of a highly thermal conductive, lightweight graphite epoxy mounting structure the battery achieved an overall specific energy of $47.13 \mathrm{Wh} / \mathrm{kg}$ and a energy density of 50.23 Wh/l. The use of battery pressure for charge control method was verified. Accomplishments to date include the successful integration of the $\mathrm{NiH}_{2}$ CPV battery with the clementine spacecraft, verification of battery performance through a qualification test program and the successful launch and on-orbit performance of the battery and spacecraft.

\section{References}

(1) J.C. Garner,"A Nickel Hydrogen Common Pressure Vessel Battery Spaceflight Experiment, " Proceedings of The 27th Intersociety Energy Conversion Engineering Conference, August 1992

W.E. Baker, "The DSPSE

Spacecraft Electrical Power system," Proceedings of The 28th Intersociety Energy Conversion Engineering Conference, August 1993

C.Hill, "Air Force Nickel Hydrogen Cell Low Earth orbit Life Test Update", Proceedings of The 27th Intersociety Energy Conversion Engineering Conference, August 1992 